\title{
Article
}

\section{Clinical governance, education and learning to manage health information}

Ellis, Beverley and Howard, John

Available at http://clok.uclan.ac.uk/4082/

Ellis, Beverley ORCID: 0000-0003-0938-1172 and Howard, John ORCID: 00000001-8936-7471 (2011) Clinical governance, education and learning to manage health information. Clinical Governance: An International Journal, 16 (4). pp. 337-352. ISSN 1477-7274

It is advisable to refer to the publisher's version if you intend to cite from the work. http://dx.doi.org/10.1108/14777271111175378

For more information about UCLan's research in this area go to http://www.uclan.ac.uk/researchgroups/ and search for < name of research Group>.

For information about Research generally at UCLan please go to http://www.uclan.ac.uk/research/

All outputs in CLoK are protected by Intellectual Property Rights law, including Copyright law. Copyright, IPR and Moral Rights for the works on this site are retained by the individual authors and/or other copyright owners. Terms and conditions for use of this material are defined in the policies page.

\section{CLoK}

Central Lancashire online Knowledge www.clok.uclan.ac.uk

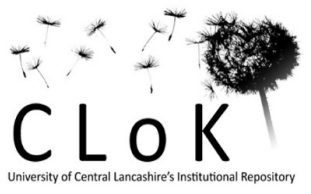




\title{
Clinical Governance: An International Journal Vol. 16 No. 4 Clinical Governance, Education and Learning to Manage Health Information
}

\begin{abstract}
Purpose

This paper suggests that the concept of clinical governance goes beyond a bureaucratic accountability structure and can be viewed as a negotiated balance between imperfectly aligned and sometimes conflicting goals within a complex adaptive system. On this view, the information system cannot be separated conceptually from the system of governance it supports or the people whose work it facilitates or hinders. The paper concludes and makes recommendations in two key governance areas: education and learning to manage health information. In practice, the lessons learned provide opportunities to inform future approaches to health informatics educational programmes.
\end{abstract}

\section{Methodology}

The study, located within the English National Health Service (NHS) between 1999 and 2005, is case study based using a multi method approach to data collection within two Primary Care Organisations (PCOs). The research strategy is conducted within a social constructionist ontological perspective.

\section{Findings}

The findings reflect the following broad-based themes: mutual adjustment of a plurality of stakeholder perceptions, preferences and priorities; the development of information and communication systems, empowered by informatics; an emphasis on education and training to build capacity and capability.

\section{Limitations}

Limitations of case study methodology include a tendency to provide selected accounts. These are potentially biased and risk trivialising findings. Rooted in specific context, their generalisability to other contexts is limited by the extent to which contexts are similar. Reasonable attempts were made to minimise any bias. The diversity of data collection methods used in the study was an attempt to counterbalance the limitations highlighted in one method by strength from alternative techniques.

\section{Practical Implications}

In practice, the lessons learned provide opportunities to inform future approaches to educational programmes.

Keywords: Clinical governance; health informatics; quality improvement; education; complex adaptive systems 


\section{Introduction}

Policy documents introduced clinical governance as a mechanism by which the public can be assured that NHS organisations have comprehensive and robust systems in place for continuously improving the quality of their services and safeguarding high standards of clinical care (DH, 1997). Clinical governance encompasses two distinct elements: the mechanistic element of ensuring systems are in place, and the more philosophical element of producing an environment in which clinical quality can flourish ( $\mathrm{DH}, 1998 ; 1999)$. The first element assumes that cause and effect can always be discovered, predicted and controlled. The second element assumes that organisational culture will foster new perspectives and insights into problem solving solutions and innovations. The report into events at the Paediatric Cardiac Unit in the Bristol Royal Infirmary suggests that change "can only be brought about with the willing and active participation of those involved in health care: the public, patients, health care professions, trusts and health authorities and government" (Kennedy, 2001). Each group may have a legitimate, but different, interpretation of quality that sometimes result in a complex mix of conflicting goals.

Proponents of clinical governance, characterised by authors such as Scally and Donaldson (1998), Dunning and Agnes (1999), Pringle (2000) and Nicholls et al., (2000), collectively claim that it provides a framework and support for quality improvement activities, drawing parallels with the concept of corporate governance by emphasising the accountability aspects of the clinical governance agenda. Donaldson (1999) suggests the development of clinical governance consolidates the 
quality agenda, through presenting one strategic direction. In response to claims that initial policy documents lack clarity about the meaning of clinical governance. Authors characterised by Nicholls et al., (2000 p.175), attempt to clarify the components of clinical governance, which are included in the following table.

\begin{tabular}{|l|}
\hline Components of Clinical Governance \\
\hline Patient-professional partnership \\
\hline Clinical effectiveness \\
\hline Risk management effectiveness \\
\hline Patient experience \\
\hline Communication effectiveness \\
\hline Resource effectiveness \\
\hline Strategic effectiveness \\
\hline Learning effectiveness \\
\hline Systems awareness \\
\hline Communication \\
\hline Ownership \\
\hline Leadership \\
\hline
\end{tabular}

Table 1 Components of Clinical Governance (Ellis, 2008; based on Nicholls et al., 2000)

Conversely, critics of clinical governance, characterised by Loughlin (2002) and Goodman (2002 p. 244) suggest issues relating to quality in the NHS include a lack of resources: "The NHS has fewer doctors and fewer nurses than the health systems of almost every comparable country"; and "lack of clarity about its true meaning and nature...allows policy makers to shift responsibility for the problems of the health service onto the workforce..." (Loughlin, 2002 p.229). The introduction of clinical governance policy $(\mathrm{DH}, 1997)$ was thought to have provided a distraction from "the core difficulties of the NHS while at the same time increasing management control of staff' (Goodman, 2002 p. 244). Clinical governance policy introduced a systematic monitoring system, based on a greater degree of control and accountability $(\mathrm{DH}$, 1997). Dunning and Agnes (1999) describe this accountability as including an individual responsibility to work within explicit standards of professional conduct and performance; engaging in continuous professional development and working in a way consistent with the corporate values and the strategic objectives of the organisation. "Incentive to behave" (motivation) is a characteristic of social learning (cognitive) 
theories that provide educators with "more effective behavioural interventions than hitherto have been available" (Rosenstock et al., 1988 p. 175). Underpinning quality improvement strategies is the axiom that poor performance typically reflects wider "system failure" (Berwick, 1989).

There are fundamental questions to answer in response to the theme of this paper. First, what is health informatics?

\section{What is health informatics?}

There are many interpretations of Health Informatics, each representing a different perspective. The document, Making Information Count (NHSIA, 2002) attempts to define Health Informatics as "The knowledge, skills and tools which enable information to be collected, managed, used and shared to support the delivery of healthcare and promote health." On this basis, health informatics is not exclusively the concern of technologists and enthusiasts but is of relevance to all those who generate, retrieve and use information and technology to support health care. The ongoing challenge for commissioners and providers of education is to embed health informatics into all clinical and non-clinical educational and training programmes as far as possible, to help health care staff manage information better in a world that is expecting more "information empowered" professionals ( $\mathrm{DH}, 2009)$.

In the NHS Next Stage Review (NSR) (DH, June 2008), Lord Darzi set out his vision of an NHS with a focus on quality as the organising principle. The report highlights that in the $21^{\text {st }}$ century, the NHS faces a particular set of unavoidable challenges, summarised as: 
- rising expectations;

- demand driven by demographics;

- the continuing development of the "information society";

- advances in treatments;

- the changing nature of disease; and

- changing expectations of the health workplace.

One problem for informatics that supports clinical practice is the tension between local specialism 'the way we do things round here' and approaches that seek to standardise, recognising that outputs may be of interest to one or more stakeholders and the need to reduce asymmetry of information. To this end, educational initiatives such as Learning to Manage Health Information (LtMHI) first developed in 1999, seek to provide a common framework in health informatics for clinical professionals to promote a common language and currency. The document emphasises that informatics is now an integral part of contemporary clinical practice by considering the three principal areas of activity in health care: working with the patient; recording the patient contact; reflection and learning. The framework reflects key assumptions and guidance developed in consultation with a wide range of stakeholders who are concerned with commissioning, developing and delivering clinical educational programmes, which encompasses the following themes:

- Essential Information Technology Skills

- Communication

- Health \& Care Records

- The Language of Health: Clinical Coding \& Terminology

- Data, Information \& Knowledge

- Protection of Individuals \& Organisations 
- Clinical Systems

- eHealth Applications

The 2009 edition of LtMHI has continued the process in light of developments in clinical practice and technology.

The reported findings of an in-depth longitudinal study identify a composite model of intersecting themes that goes beyond controls, compliance assurance and archiving of corporate policies and protocols, to enable non-hierarchical, exploratory models of problem appreciation and problem solving by a plurality of stakeholders (Ellis, 2010). Clinical governance is viewed as a negotiated, social activity rather than a fully codified, legislated rule set. This paper is an extension of this view, with a particular emphasis on factors relating to the development of educational programmes and health informatics. An emphasis on the responsibilities of individuals highlights the importance of lifelong learning and role of health informatics in actively managing individual performance. Complex adaptive systems and social learning models are a different way of thinking about complex situations, which consider the conditions that contribute to the environment that such situations operate within that may include social, political, technological and financial influences.

\section{Systems Based Thinking and its Relation to Learning Theories}

Open systems theories evolve out of the work of Bertalanffy, a biologist, which takes into account the dynamic whole of the organism, its interaction with its environment and permeable boundaries (Flood, 1999). Second-order systems based thinking moves away from simple objective observation to understand humans as participants 
in systems that allows for the flow of energy (motivation, information and innovation) and networked interactions. The origins of learning theories can be traced to Lewinian field theory (Lewin, 1936; 1947); cognitive theory and humanistic psychology (Knowles, 1984; Brookfield, 1986; and Atkinson et al., 1996). According to the cognitive perspective, learning is an organisms' ability to represent aspects of the world mentally and then operate on these mental representations rather than the world itself (Atkinson et al., 1996). Learning theories identify the role of feedback in sustaining and improving human performance at work that involves single loop and double loop learning, associated with proactively challenging and influencing a range of different or conflicting perspectives (Senge, 1990). Similarly, learning theories suggest exploratory models of problem appreciation and problem solving by a plurality of stakeholders that reflect practical day-to-day concerns, relevant to participants' daily working lives and activities (Kolb, 1984; Hayes, 1995 and Pendleton, 1995). The importance of education and professional support that focuses on experiential learning as a tool to change behaviour is identified (Schein, 1985; Schön, 1983; Schön and Rein, 1994; Berwick et al., 1992; Berwick, 1996; 1998). Kolb (1984) identifies an experiential learning model that has four phases:

- Concrete experience

- Reflective observation in which the learner rethinks through what has occurred

- Active experimentation

- Abstract conceptualisation, in which the learner normalises the processes and knowledge.

The model is premised on changing the basic assumptions the way we do things round here' that result from past learning. Learners go through a cycle in which they acquire knowledge, assimilate, experiment and then normalise the learning into their 
daily work informed by 'plan-do-study/check-act' feedback loops (Senge, 1990). Contemporary learning models manifest an understanding of the need for skills and knowledge to be embedded in experience, and allow reflection on that experience to create new meaning and enduring changes in behaviour.

Social learning theories emphasise the role of expectations held by the individual. "Behaviour, in this perspective, is a function of the subject value of an outcome and of the subjective probability (or 'expectation') that a particular action will achieve that outcome" (Rosenstock et al., 1988 p.176), suggesting that behaviour is determined by expectancies and incentives. In this context, underlying trends influencing management approaches to quality improvement programmes within primary care include:

- explicit rules and regulations supplementing the implicit codes governing professional/patient relations (Baker, 2000; Baker, 2001; Baker and Grol, 2002).

- development of a balance of power between various judgements on quality (Ferlie, 1994; Ferlie et al., 1996).

- $\quad$ an increasing status of the GP within health services (Meads, 1996; Rigby et al., 1998).

Davies and Mannion (1999 pp 247-8) write that the following developments led to the increasing importance of quality towards the end of the $20^{\text {th }}$ century:

- An increase in the evidence-base of what worked in clinical practice

- Sophisticated data systems and the expertise to interrogate them

- Widespread variation in clinical practice and outcomes 
- Cost cutting by managers with apparent less regard for the quality of care

NHS quality improvement programmes provide operational frameworks that incorporate various mechanisms to help bring about clinical governance through regulation, incentives, Continuing Professional Development (CPD), peer review and organisational quality improvement methods.

While the above theoretical models begin to account for the significance of the interactions between human participants and educational initiatives, they fail to address the nature of clinical governance. The next section introduces the case studies.

\section{Methodology}

The longitudinal study, located within the English National Health Service (NHS) between 1999 and 2005, is case study based using a multi method approach to data collection within two Primary Care Organisations (PCOs). The research strategy is conducted within a social constructionist ontological perspective. This approach contextualises clinical governance, the trend towards collaborative partnerships and federated models of practice, enabled by developments in primary care informatics (Ellis, 2010).

Limitations of case study methodology include a tendency to provide selected accounts. These are potentially biased and risk trivialising findings. Rooted in specific context, their generalisability to other contexts is limited by the extent to which contexts are similar. One researcher's own interpretation of reality, as a social construction, may not resonate with that of another. Reasonable attempts were made 
to minimise any bias. The diversity of data collection methods used in the study was an attempt to counterbalance the limitations highlighted in one method by strength from alternative techniques. The methods used to collect and analyse the data from a range of sources, including respective strengths and weaknesses, are illustrated in an overview of the case study methodology in Table 2 that follows:

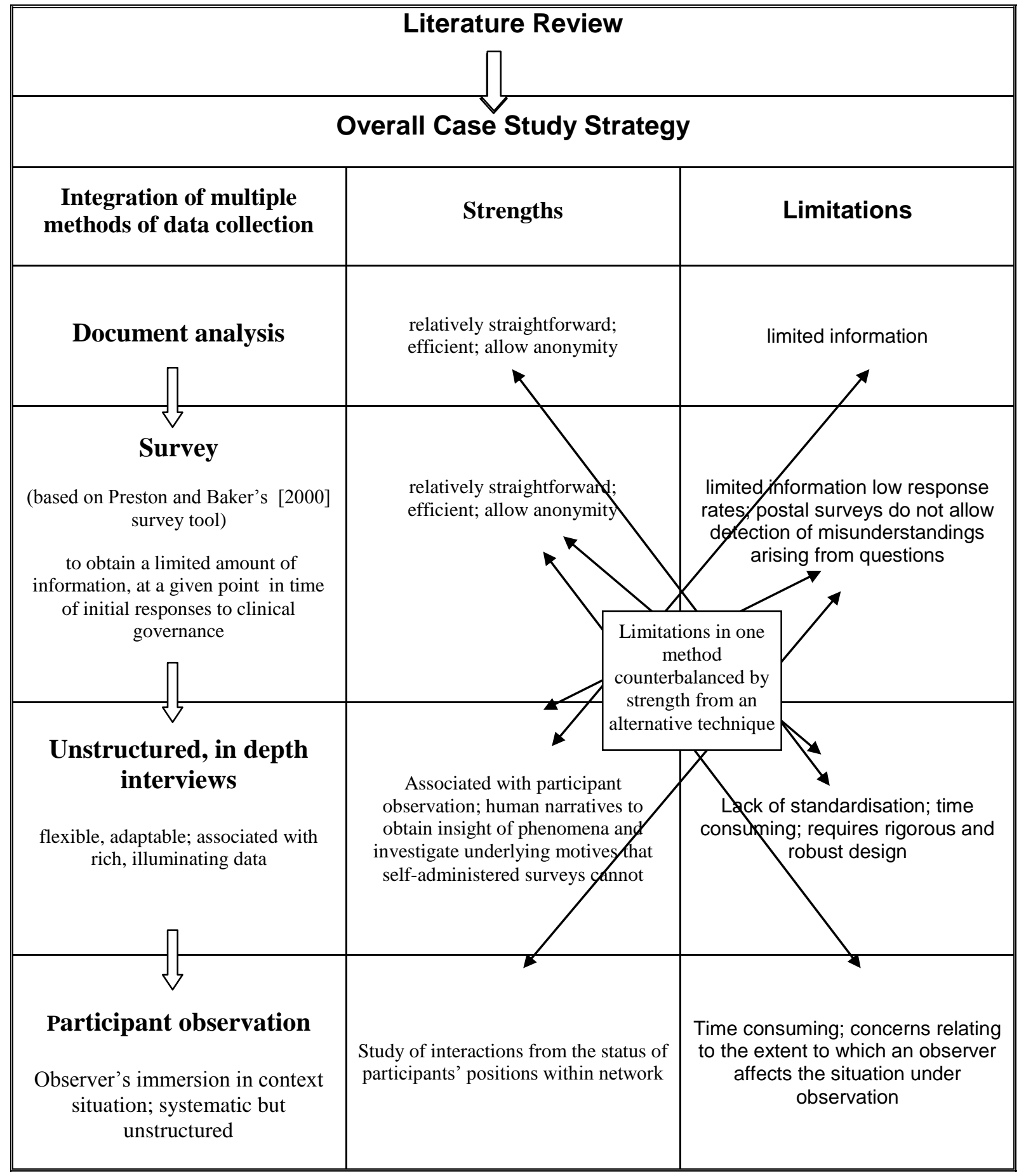

Table 2 Overview of the Case Study Methodology (Ellis, 2008) 


\section{Choice of case study sites}

The choice of case study site was determined by the purpose of this research study; the convenient sampling of PCO case studies focused on established communication links and close relationships with participants facilitating access to undertake this study as the researcher worked within the NHS case study localities. This provided a number of advantages in the study that included access. The researcher was also aware of a down side to this privileged position in relation to the potential to introduce bias. Reasonable attempts to minimise any bias were made. For example, a 100\% sample was applied to postal survey in each case study; in addition, volunteer interviewees were requested, issuing a letter and information pack to each case study clinical governance committee, to each practice and primary health care team. The letter informed potential respondents of the role of the researcher and the purpose of any involvement. It was stressed in both the written material and with verbal reassurances that there was no obligation to participate. It was emphasised that refusal to be involved, or any matter divulged during interview would not jeopardise the working relationship between the researcher and participants. The researcher's participant posture was necessary in order to gain first-hand experience of the workings of clinical governance. It can be argued that this suggestion facilitated the development of a rapport that improved the amount and depth of empirical data collected counterbalancing negatives associated with this approach, such as those associated with the potential for bias.

The findings are not intended to be generalisable to disparate contexts. As described earlier, the heterogeneous factors of English NHS primary care suggest the importance of context. Approaches that seek to emphasise generalisability are unlikely to provide sufficient description of specific local organisation and context. The study captures the experiences and perceptions of participants involved locally in implementing clinical governance and coordinated actions that include establishing educational programmes to support learning to manage health information. The sampling strategy, therefore, is purposive in nature. 
General characteristics of the studied, geographically linked, PCOs are described next. The first PCO: semi-rural with approximate population of 70,000, 11 practices and multidisciplinary primary care teams including 37 GP, was established in 1999 as a level 2 Primary Care Group (PCG), took devolved responsibility for managing a healthcare budget of $£ 618$ per capita. PCO boundary coterminous with relevant Social Services Department.

The second PCO - urban, approximate population of 150,000; one acute trust; 25 practices and multidisciplinary primary care teams including 84 GPs, was established in 1999 as a level 2 PCG; took devolved responsibility for managing healthcare budget of $£ 665$ per capita; Coterminous PCO boundary with Social Services Department.

The case study design led to a mix of quantitative and qualitative data - the type of data led the plan of analysis, each type of data being analysed separately. For example, survey responses allowed analysis of attribute data as to the strength of agreement, or disagreement with statements. The attribute data was subsequently presented as values of particular variables that were named and defined with corresponding data input using an incidence data matrix. Thirty in-depth interviews were conducted with self-selecting volunteers from multiple disciplines that revealed dimensions of approaches, perceptions of clinical governance and learning programmes from those actively engaged within the two studies PCOs. Interviewees consisted of 17 males, 13 females; GPs, Clinical Governance Lead, Chief and Assistant Executives, managers, pharmaceutical advisor, nurses and CPD team members. Following transcription, text was uploaded into software application (Atlas $\mathrm{Tl}^{\odot}$ - a registered trademark of Scientific Software Development, Berlin). The central analytical approach adopted in the development of themes and categories was open coding, derived from interviewees' own words. 
The following section introduces Complex Adaptive System (CAS) theories that are a valuable tool to help make sense of natural phenomena, which include human responses to problem solving within organisations.

\section{Complex Adaptive Systems}

A complex adaptive system (CAS) approach, in this context of this paper, is interpreted as a framework that assists in thinking about the nature of quality improvement and learning programmes. Drawing on the literatures of CAS it is argued that the governance of quality improvement is based on three propositions. The first proposition: the meanings attributable to the explanations available to a PCO for achieving quality improvement are multifarious. The argument: PCOs operate in a complex network of general practices, Primary Health Care Teams, Social Services and other local agencies, each of which has some influence on the governing activities of quality improvement. Empirical support for this proposition will be found in organisations that apply CAS principles that engender mutual recognition of common or complementary strategic agendas. The second proposition: the scope and influence of quality improvement programmes self-organise across each PCO. The argument: clinical governance systems update based on experience, any part can influence other parts through connectedness and interdependencies. Empirical support for this proposition will be found in the activities that include regulation; incentives, CPD, peer review, organisational QI methods and so on and interdependencies among each organisations change management programme. The third proposition: given the combination of clinical governance activities and information exchanges, patterns of collaborative behaviour exist in each organisation. The argument: within each change management programme are combinations of 
activities that distinguish an organisations response to the introduction of policy and ever changing environment. Empirical evidence for this proposition will be found in improved symmetry between different levels of the system.

Key elements and principles that characterise a CAS are introduced below (Reynolds, 1987; Kauffman, 1993 and Gell-Mann, 1994). They form useful models of the types of social interactions between professionals looking to implement change (Cilliers, 1998; Anderson, 1999; Ellis, 2010).

CAS Element - Multiple agents, different world-views

\section{Principle}

- Accept the democratic principles that contribute to the development of quality improvement programmes and ultimately to the emergence of self-regulated, evolutionary PCOs;

\section{CAS Element - Self-organising networks}

\section{Principles}

- Respect for the pervasive nature of interlinked interactions; it is in the patterning of behaviours that emerge that contribute to the governance of quality improvement programmes;

- Observe that there may be no central direction.

CAS Element - Coevolution and system adaptation

\section{Principles}

- Respect for ecologies, avoid disturbing an ecology with major changes; 
- Allow time for properties to emerge;

The diversity of these principles demonstrates that adopting a CAS framework does not lead to any single or unified model of quality improvement. Instead, insight may prove significant in terms of interpreting what is 'going on' in response to change instigated by policy.

The application of the conceptual framework helps to provide insight and to generate a resonance with the experiences of those involved. The aim is to reflect on the main themes, drawing on the principles of CAS to explain and improve understanding.

\section{Results}

The following broad-based themes will be discussed:

- Mutual adjustment of a plurality of stakeholder perceptions, preferences and priorities

- The development of information and communication systems, empowered by informatics

- Emphasis on education and training to build capacity and capability

Multiple stakeholder perceptions, preferences and priorities

Key themes identified in this section represent the experiences of those involved, supported by individual accounts expressed using quotes. These capture the extent 
that prior experience, leadership and knowledge is perceived as relevant to individual participants.

With regard to the first theme, each PCO undertook a campaign to raise awareness of clinical governance. Previously active educational enthusiasts instigated a series of collaborative events that included focus groups, consultations and themed educational events. Social interaction led to mutual adjustment of a plurality of stakeholder perceptions, preferences and priorities, expressed as “..not only for clinical governance but just to cut down the barriers of designation... to be able to interact, almost socially, breaks down the barriers, which helps when you are communicating at work or liaison with other practices" (Nurse). Furthermore, voluntary social interaction with multidisciplinary colleagues was noted "I would attend things like that (clinical education society meetings) more voluntarily than picking up a magazine and reading it in an evening" (Nurse). The overall aim was to generate a culture that facilitated learning with the intention that this would lead to quality improvement, expressed as: "I think bringing professionals together is very powerful indeed and I think that the Clinical Education Society (CES) has been very, very good for achieving that and significant numbers turn up regularly" (Chief Executive). Supported by: "I think it (CES) also builds a cultural networking, which is also just as important as the actual topic that's being discussed" (Chief Executive). The importance of this influence is referred to using positive terms, as expressed in the following quote: "I think my feeling is we had an extremely good lead at the beginning that was very enthusiastic and very keen to spend time and give time to actually develop it (clinical governance) and that I think actually helped the process move forward..... I think the clinicians recognised that they did have a say, that they did make 
a difference and that people did listen to them" (Chief Executive). Solutions emerged from ideas perceived to work, as expressed in the following account: "I think the biggest thing that has advanced GPs working together is TMS .... that is already well integrated and part of a different team" (General Practitioner). The orientation of the findings suggests a level of existing appreciation of the way in which professional groups behave and communicate.

A major emphasis observed during the study was the use of incentives that included 'protected time' and financial incentives, to encourage the sharing of ideas and information that focused on themed health improvement programmes.

The application of the CAS framework provides insight into the emergent, socially constructed nature of the process of implementation; results are unpredictable. Clinical governance emerges from a set of complex interactions, rather than from rational planning. The theme suggests that the effectiveness of individuals may be related to their ability to acquire and learn specific skills and knowledge within available resources, addressed next.

The development of information and communication systems, empowered by informatics

Key themes in this section reflect networked activities, empowered by informatics, that support the delivery and planning of quality health care and a need to offload risk. A high degree of dissatisfaction with existing information services at the outset of the study highlights a need to strengthen and improve feedback, illustrated by the following quote by a nurse that emphasised a need to develop: "better 
communication...updated information...all levels". Subsequently, "...the information's coming in (from primary care) which enables us to put more man hours into other areas ... and action, without that we don't know if anything that we've done has made the slightest bit of difference" (Manager).

The findings reported in this section can be summarised as the development of mechanisms that support collaborative ways of working for the purpose of delivering and planning quality healthcare, comparison and feedback. There is some overlap between this theme and those presented next.

\section{Emphasis on education and training to build capacity and capability}

The final theme highlights an emphasis on education and training to raise awareness of the nature of clinical governance, related quality concepts, trend towards integrated organisations supported by the use of technology, stimulate innovative ideas, build capacity and capability. The findings reflect a continuum of individual and organisational learning focused on acquisition of skills and knowledge deployed in the workplace that contribute to the planning and delivery of quality care, change in attitudes and behaviours.

A wide array of education and training initiatives, which include significant event reviews; clinical audit meetings; action learning events; clinical education society meetings; multidisciplinary and uni- disciplinary health care team meetings are supported by a range of training and academic qualifications. The variety of approaches suggests knowledge and awareness of the need to consider the 
situatedness of learning and difficulty of restructuring meaning in new ways (Honeyman, 2001). Topics include the management and delivery of chronic disease, supported by protected time, to act, reflect and embed principles in practice. An innovative approach is observed that encourages creativity and viewing problems from different angles; reflecting and questioning practice and working with others to make sustainable improvements; thinking outside of the box being solution and impact focused (Ellis, 2002). The underpinning ethos is suggested to be based upon a belief that individual competency is the integration and application of knowledge, skills and behaviour.

These findings support the view that the development and implementation of clinical governance in two PCOs is dependent on empowered autonomous individuals, equipped with the skills, knowledge and competencies to integrate informatics within wider plans of improvement. Their motivation for change is explained as a need to develop communication systems, empowered by informatics; developing practical skills and tools in response to the challenges brought about by social, economic, environmental and political changes. The overall objective is expressed as a need to retain, at a local level, the right to self-regulate work processes. On this basis, the study shows that the implementation and development of clinical governance programmes in the PCOs cannot be explained by positivist approaches alone; a strategic orientation that pursues one particular world view is likely to distort perceptions of the effectiveness of quality improvement programmes. 


\section{Lessons Learnt}

Arising from the results of the study there is a need to shift NHS policy makers thinking from a hierarchical command and control emphasis, which advises managers what to do to ensure that the organisation achieves goals in an optimum way. The experience of those described within the study conflict with the notion that performance is optimised when structures and processes are introduced based on the assumption that the quality of healthcare is predictable.

The results suggest that quality improvement systems develop locally based on information, knowledge and experience exchange, any part of the system can influence other parts through networks and interdependencies. On this basis, a CAS approach accommodates coping tactics that emerge in recognition that paradox and anxiety are characteristics of systems that evolve. A key issue is that the study provides a particular focus on the need to develop practical skills, knowledge and competencies that are applied in the workplace, linking those involved with the implications of their actions and a wider dimension of organisational relations.

\section{Recommendations}

Central to the recommendations is the belief that the best decisions are based on the best information. However even equipped with the best information, decision makers need a range of professional skills and abilities in order to be able to utilise information in order to transform results. Educational programmes need to emphasise this central role of high quality information in the support of decision 
making and inspire positive change by bringing health informatics to life through innovation, research-informed approaches and real-world practicality.

Below is a graphical exemplar that shows the ways in which an educational programme module can reflect external environmental influences in order to equip students with appropriate knowledge and skills of informatics to apply in their workplace.

\begin{tabular}{|c|c|}
\hline Policy & Leadership Qualities \\
\hline $\begin{array}{l}\text { Liberating the NHS: Equity and Excellence (July,2010) } \\
\text { Legislative framework and next steps (December,2010) } \\
\text { Report of the arms length bodies review (July 2010) } \\
\text { Developing the health care workforce (2010) } \\
\text { QIPP programme. } \\
\text { Operating framework for the NHS in England (2011-12) }\end{array}$ & $\begin{array}{l}\text { Creating opportunities to bring individuals and groups } \\
\text { together to share information and achieve goals } \\
\text { Identifying opportunities for service improvement } \\
\text { Scanning for ideas, best practice and identifying emerging } \\
\text { trends } \\
\text { Acting as positive role model for innovation }\end{array}$ \\
\hline \multicolumn{2}{|c|}{$\begin{array}{l}\text { Knowledge Based Management and Leadership for Care } \\
\text { Leadership and Management: principles and practice } \\
\text { The Management of Knowledge } \\
\text { Whole Systems Thinking } \\
\text { Using Knowledge to Deliver Sustainable Service Improvement } \\
\text { Using Knowledge to Support Decision Making } \\
\text { Risk Management }\end{array}$} \\
\hline $\begin{array}{l}\text { Achieving financial targets and reducing waste } \\
\text { Maintaining and improving quality and healthcare outcomes } \\
\text { Whole systems development } \\
\text { Transfer of PCT Functions } \\
\text { Comprehensive Spending Review: Efficiency Savings }\end{array}$ & $\begin{array}{l}\text { Leadership Theory } \\
\text { Change management } \\
\text { Strategy } \\
\text { Management theory. }\end{array}$ \\
\hline Challenges & Theory \\
\hline
\end{tabular}

Table 3 Interaction between module content with the environment

There is a need for educational programmes to demonstrate in particular:

- Productive partnerships that encourage ownership of the educational programme to ensure it meets NHS needs by effectively involving NHS staff, 
student participants, service users, academic staff and other stakeholders in the design; ensure learning outcomes map to relevant professional bodies requirements and competency frameworks; utilises evidence-based, cost effective, proven innovative delivery methods and evaluation of the learning.

- A focus on enabling students to feel confident with sustainable change, able to lead and innovate in their everyday work.

- Recognition of the need to be flexible and responsive.

There is a need to consider the benefits of eLearning. Apart from developing a generic understanding of systems found in practice, eLearning programmes can facilitate multidisciplinary training using complex scenarios and therefore promote team working and leadership development. ELearning is not simply cost effective but can address the need to ensure equality of opportunity for the whole range of students from all backgrounds. Examples of evidence include Larsen (1992) who found no differences in post-test scores based on learner style preferences and Kass et al. (1998) who found that using computer simulators actually eliminated a gender gap that was present when traditional learning was used. Hawthorne et al (2009) found that eLearning was preferred by a majority of students whilst there was no difference in achievement compared to more traditional delivery of a module on cultural diversity as part of a clinical curriculum. Paechter et al (2010) have shown that there are two aspects which contribute strongly to learning achievements and course satisfaction when using an eLearning delivery methodology; students' achievement goals and instructor support. ELearning based educational programmes 
can also have significant benefits for patients and carers; online resources can contribute to patient empowerment, enable self-management of chronic and shortterm conditions and promote communities of support for carers (DH, 2009).

\section{Conclusion}

The study has highlighted that educational programmes, which support quality improvement empowered by health informatics, are increasingly less determined through bureaucratic lines of authority, more often through aspects attributable to an emergence of a combination of formulations. With a change in perspective comes the possibility of a different way of acting and relating. Various perspectives, presenting potentially conflicting views of quality have been described. The complexity of these perspectives can be partially attributed to a greater emphasis on inclusion of stakeholders that include patients, and the public in general in healthcare decision-making. This approach can contribute a degree of flexibility and resilience to problem solving capability within the whole system. On this basis, a CAS approach accommodates coping tactics that emerge in recognition that paradox and anxiety are characteristics of systems that evolve.

The implications are that educational programmes need to ensure that participants are equipped to demonstrate the personal qualities and will have the required values and behaviours, key skills, and energy that will be required to provide a patient-led

healthcare system. Participants need to learn to exploit the analysis and use of information within the current economic context.

It is suggested that eLearning will play an increasingly important role in healthcare. It enables the rapid creation and dissemination of quality assured learning content and 
provides the opportunity for more flexible access to learning with sharing of learning

resources across the NHS, including Social Care and the Education sector $(\mathrm{DH}$, 2009).

\section{References}

Anderson, P., (1999); Complexity Theory and Organization Science, Organization Science, 10, No.3, May-June, pp 216-232.

Atkinson, R.L., Atkinson, R.C., Smith, E.E., Bem, D.J. and Nolen-Hoesema, S.,(1996); Hilgard's Introduction to Psychology, Harcourt Brace, Fort Worth.

Baker, R., (2000); Reforming primary care in England - again. Plans for improving the quality of care, Scandinavian Journal of Primary care, 18, pp 72-74.

Baker, R. (2001); Principles of quality improvement. Part one - defining quality, Journal of Clinical Governance, 9: 89-91.

Baker, R. and Grol, R. (2002); Principles and models for quality improvement, in Jones,

R. (Ed.) Oxford Textbook of Primary Medical Care. Oxford: Oxford University Press.

Baker, R., Lakhani, M., Fraser, R., and Cheater, F., (1999); A Model for Clinical Governance in Primary Care Groups, BMJ, 318, pp 779-83.

Berwick, D.M., (1989); Continuous improvement as an ideal in health care. N Eng J Med 1989: 320:pp 53-56.

Berwick, D., Enthoven, A., and Bunker, J., (1992); Quality Management in the NHS; the Doctor's Role, BMJ, 304, pp 304-308.

Berwick, D., (1996); A Primer on Leading the Improvement of Systems, BMJ, 312, pp 619-622.

Berwick, D., (1998); Developing and Testing Changes in Delivery of Care, Annals of Internal Medicine, 128, pp 651-656.

Brookfield, S. D., (1986); Understanding and Facilitating Adult Learning, Open University Press, Milton Keynes.

Cilliers, P., (1998); Complexity and Post-modernism. Routledge, London.

Davies, H. T. , and Mannion, R., (1999); Clinical governance: striking a balance between checking and trusting, in Smith, P.C., (Ed.), Reforming Markets in Healthcare, Open University Press, Bucks. Department of Health, (1997a); The new NHS. Modern, Dependable, HMSO, London, Cm3807. Department of Health, (1998a); A First Class Service. Quality in the New NHS, HSC(98)113, HMSO, London P33.

Department of Health, (2002); Making Information Count: A human resources strategy for health informatics professionals, HMSO, London.

Department of Health, (2008); NHS Next Stage Review, HMSO, London.

Donaldson, L. J. (1999); Clinical Governance: Quality improvement as a duty not a choice, Healthcare Quality.

Dunning, M., and Agnes, P., (1999); What Is Clinical Governance? A Workable Definition, Healthcare Quality.

Ellis, B., (2002); Identification of the critical success factors involved in the implementation of clinical governance arrangements within primary care, Informatics in Primary Care, 10, pp 19-23.

Ellis, B., (2008); Managing governance programmes in primary care: lessons from case studies of the implementation of clinical governance in two primary care trusts, PhD Thesis, University of Central Lancashire, Preston.

Ellis, B., (2010); Complexity in Practice: Understanding primary care as a complex adaptive system. Informatics in Primary Care, 18, pp135-40.

Ferlie, E., (1994); Characterising the 'New Public Management', Paper presented at the Annual Conference of the British Academy of Management, September, 12-14.

Ferlie, E., Ashburner, L., Fitzgerald, L., and Pettigrew, A., (1996); The New Public Management in Action, Oxford University Press, Oxford.

Ferlie, E., Shortell, S., (2001); Improving the Quality of Healthcare in the United Kingdom and the United States; A Framework for Change , The Millbank Quarterly, 79, 2, pp 281-314.

Flood, R.L., (1999); Rethinking the $5^{\text {th }}$ Discipline, Routledge, London.

Ellis, B., (2001); Agreeing a PCG Coding Policy, BCS Healthcare Computing, 2001 (Conference Proceedings). 
Gell-Mann, M., (1994); The Quark and the Jaguar, Freeman, New York.

Goodman, N. W., (2002); Clinical Governance: vision or mirage? Journal of Evaluation of Clinical Practice, 8, (2), pp 243-249.

Greenhalgh, T., Eversley, J., (1999); Quality in General Practice, King's Fund Publishing, London. Hawthorne, K. Prout, H. Kinnersley, P. Houston, H. (2009), Evaluation of different delivery modes of an interactive e-learning programme for teaching cultural diversity, Patient Education and Counselling, $\mathbf{7 4}$ (2009) pp 5-11.

Hayes, T. M., (1995); Continuing medical education: A personal view, BMJ, 310, pp 994-996.

Handisides, S., (1994); Building morale through personal development, BMJ, 308, pp 114-116.

Honeyman, A., (2001); Consultancy or Control? Models of Change Management at the Interface

between the Modernisation Agency, Primary Care Groups and an Inner London Health Authority, MSc Thesis.

Kass, S. J., Ahlers, R. H. and Dugger, M. (1998); Eliminating gender differences through practice in an applied visual spatial task. Human Performance, 11, pp 337-49.

Kauffman, S.A., (1993); Origins of Order: Self Organisation and Selection in Evolution, Oxford

University Press, Oxford.

Kolb, D.A., (1984); Experiential Learning - Experience as a Source of Learning and Development,

Prentice Hall.

Knowles, M. S., (1980); The Modern practice of adult education: from pedagogy to androgogy. 2nd, Cambridge Books, New York.

Knowles, M., (1984); The Adult Learners. A Neglected Species. Gulf Publishing.

Larsen, R. E. (1992); Relationship of learning style to the effectiveness and acceptance of interactive

video instruction. Journal of Computer-based Instruction, 19, pp17-21.

Lewin, K., (1936); Principles of Topological Psychology, McGraw Hill, New York.

Lewin, K., (1947); Feedback Problems of Social Diagnosis and Action, Part II-B

of Frontiers in Group Dynamics, Human Relations, 1, pp 147-153.

Loughlin, M., (2002); On the buzzword approach to policy formation, Journal of Evaluation in Clinical Practice, 8, 2, pp 229-242.

Meads, G., (1996); A primary care led NHS. Oxford: Churchill-Livingstone.

National Health Service (General Medical Services Contracts) (2004); Regulations, HMSO.

National Health Service Executive, (1999a); Clinical Governance: In the New NHS, Health Service Circular 1999/065 16 March.

National Health Service Executive, (1999b); Governance in the New NHS, Health Service Circular, 1999/123, 21 May.

NHS Information Authority, (1999); Learning to Manage Health Information, HMSO, London.

NHS Information Authority, (2002); Learning to Manage Health Information: Moving Ahead, HMSO,

London.

Nicholls, S., Cullen, R., O'Neill, S., and Halligan, A., (2000); Clinical Governance: its origins and its foundations, Clinical Performance and Quality Healthcare, 8, No. 3, pp 172-178.

Pendleton, D., (1995); Professional development in general practice: problems, puzzles and paradigms, Br J General Practice, 45, pp 377-381.

Paechter, M. Maier, B. Macher, D. (2010), Students' expectations of, and experiences in e-learning:

Their relation to learning achievements and course satisfaction. Computers \& Education, 54; pp222229.

Pringle, M., (2000); Participating in clinical governance. BMJ; 321(7263), pp 737-740.

Reynolds, C. W., (1987); Flocks, Herds and Schools: A distributed behaviour model, proceedings of SIGGRAPH '87, Computer Graphics, 21, 4, pp 25-34.

Rigby, M., Roberts, R., Williams, J., Clark, J., Savill, A., Lervy, B., and Mooney, G., (1998); Integrated record keeping as an essential aspect of a primary care led health service, BMJ, 317, pp 579-582.

Rosenstock, I.M., Strecher, V.J., Becker M.H., (1988); Social Learning Theory and the Health Belief Model, Health Education Quarterly, 15, 2, pp 175-183.

Scally, G., and Donaldson, L. J., (1998); The NHS's 50 anniversary. Clinical governance and the drive for quality improvement in the new NHS in England,317, pp 61-65.

Schein, E. H., (1985); Organisational Culture and Leadership, Jossey-Bass, London and San

Francisco.

Schön, D., (1983) The Reflective Practitioner, How Professionals Think in Action, Temple Smith, London.

Schön, D.A., and Rein, M., (1994); Frame reflection : toward the resolution of intractable policy controversies, Basic Books, New York. 
Senge, P., (1990); The Fifth Discipline: The Art and Practice of the Learning Organisation, Century Business, New York.

Smith, L.F.P., and Harris, D., (1999); Making clinical governance work for you. BMJ, 322, pp 1608. 